OPEN ACCESS

Edited by:

Yuxin Tang,

University of Macau, China

Reviewed by:

Linghui $Y u$,

Nanyang Technological

University, Singapore

Weijiang Xue,

Massachusetts Institute of

Technology, United States

Litong Wang,

University of Macau, China

*Correspondence:

Peichao Lian

lianpeichao@126.com

Bingbing Tian

tianbb2011@szu.edu.cn

tThese authors have contributed equally to this work

Specialty section:

This article was submitted to

Electrochemistry,

a section of the journal

Frontiers in Chemistry

Received: 12 December 2019 Accepted: 04 February 2020

Published: 21 February 2020

Citation:

Zuo Z, Zhuang L, XU J, Shi Y, Su C, Lian P and Tian B (2020) Lithiophilic

Silver Coating on Lithium Metal

Surface for Inhibiting Lithium

Dendrites. Front. Chem. 8:109.

doi: 10.3389/fchem.2020.00109

\section{Lithiophilic Silver Coating on Lithium Metal Surface for Inhibiting Lithium Dendrites}

\author{
Zefu Zuo ${ }^{1,2 t}$, Libin Zhuang ${ }^{2 t}$, Jinzhuo $\mathrm{Xu}^{2}$, Yumeng Shi ${ }^{2}$, Chenliang $\mathrm{Su}^{2}$, Peichao Lian ${ }^{1 *}$ \\ and Bingbing Tian ${ }^{2 *}$ \\ 'The Higher Educational Key Laboratory for Phosphorus Chemical Engineering of Yunnan Province, Faculty of Chemical \\ Engineering, Kunming University of Science and Technology, Kunming, China, ${ }^{2}$ International Collaborative Laboratory of 2D \\ Materials for Optoelectronics Science and Technology of Ministry of Education, Institute of Microscale Optoelectronics, \\ Shenzhen University, Shenzhen, China
}

Li metal batteries (LMBs) are known as the ideal energy storage candidates for the future rechargeable batteries due to the high energy density. However, uncontrolled $\mathrm{Li}$ dendrites growing during charge/discharge process causes extremely low coulombic efficiency and short lifespan. In this work, a thin lithiophilic layer of Ag was coated on the bare Li surface via a thermal evaporation method, which alleviated volume variations and suppressed Li dendrites growth during cycling. As a result, a long lifespan of $250 \mathrm{~h}$ at a current density of $1 \mathrm{~mA} \mathrm{~cm}-2$ was achieved in the symmetric cell when using the Ag-modified Li foil (Ag@Li). The $\mathrm{LiFePO}_{4} \mid \mathrm{Li}$ full cell demonstrated an excellent cycling performance with a high specific capacity of $131 \mathrm{mAh} \mathrm{g}^{-1}$ even after 300 cycles at 0.5 C. This study offers a suitable method for stabilizing Li metal anodes in LMBs.

Keywords: Li metal batteries, thermal evaporation, Li dendrites, Ag layer, lithiophilic layer

\section{INTRODUCTION}

The advent of electric vehicles (EVs) has spurred the need for high energy density batteries (Tarascon and Armand, 2011; Xiang et al., 2011; Li et al., 2016; Xue et al., 2019a). The capacity of the widely used lithium ion batteries (LIBs) using traditional graphite anodes with $372 \mathrm{mAh} \mathrm{g}^{-1}$ are difficult to catch up with the demand of the current energy market (Whittingham, 1976; Choi et al., 2012; Goodenough and Park, 2013; Choi and Aurbach, 2016; Schmuch et al., 2018). Li metal is recognized as one of perfect anodes for LIBs owing to its lowest reduction potential ( $-3.04 \mathrm{~V}$ vs. the standard hydrogen potential electrode) and ultrahigh theoretical specific capacity (3,860 mAh $\mathrm{g}^{-1}$ ) (Xu et al., 2014; Yang et al., 2015; Lin et al., 2017; Wang A. et al., 2018; Xue et al., 2019b). Nevertheless, working risks come from the uncontrolled Li dendrites formation and side-reactions of highly active Li with the electrolyte, which will induce Li metal batteries (LMBs) short circuit (Aurbach et al., 2002; Qian et al., 2015; Takeda et al., 2016; Yan et al., 2016; Guo et al., 2017; Wang H. et al., 2017; Sahalie et al., 2019). To settle these problems, great efforts have been devoted to improve the stability of Li metal anode. For instance, diverse electrolyte additives were used to prevent side reactions of Li with organic electrolytes (Grande et al., 2015; Li et al., 2015; Zheng et al., 2017; Zhang X. Q. et al., 2018). Solid-state electrolytes with high mechanical strength and lithiophilic three-dimensional (3D) hosts with increased specific surface area were also developed 
for LMBs to enhance the safety of $\mathrm{Li}$ anodes (Han et al., 2017; Wang S. H. et al., 2017; Jiang et al., 2018; Qi et al., 2018; Yue et al., 2018; Chen X. et al., 2019). Although certain improvements in stability of Li metal anodes have been made, some shortcomings should be considered when they are applied in practical application of LMBs. In simple terms, large voltage hysteresis appeared in the batteries using solid electrolyte due to the poor ionic conductivity of solid electrolyte and the large interfacial resistance of the electrode and solid electrolyte (Kamaya et al., 2011; Bouchet et al., 2013). Electrolyte additives for SEI stabilization can only reinforce SEI formation and prevent dendrite propagation (Cheng et al., 2017; Zhang X. Q. et al., 2018). 3D skeletal structures were prone to collapse under high current densities (Ye et al., 2017; Wang L. et al., 2018). Expect from the above methods, covering the surface of the Li foil with a lithiophilic layer is another effective way to protect the Li metal anode. Till now, it has been reported that $\mathrm{ZnO} /$ carbon nanotube $(\mathrm{CNT}), \mathrm{Au}, \mathrm{S}, \mathrm{P}, \mathrm{Sn}$, and $\mathrm{Si}$ have been reported to inhibit $\mathrm{Li}$ dendrites (Lin et al., 2018; Zhang X. Q. et al., 2018; Guo et al., 2019; Liang et al., 2019; Xia et al., 2019). Chen et al. used sulfur vapor to react with $\mathrm{Li}$ then transform into $\mathrm{Li}_{2} \mathrm{~S}$ on the $\mathrm{Li}$ surface (Chen H. et al., 2019). The $\mathrm{Li}_{2} \mathrm{~S} @ \mathrm{Li} \mid \mathrm{Li}_{2} \mathrm{~S} @ \mathrm{Li}$ cell maintained an overvoltage of $95 \mathrm{mV}$ after $600 \mathrm{~h}$ at the current density of $2 \mathrm{~mA} \mathrm{~cm}^{-2}$ and fixed capacity of $5 \mathrm{mAh} \mathrm{cm}^{-2}$. The high ionic conductivity of $\mathrm{Li}_{2} \mathrm{~S}$ relieved non-uniform $\mathrm{Li}$ ions flux and suppressed Li dendrites, but it is almost an insulator. Kim et al. proposed a method that phosphorene is added dropwise on the Li foil surface (Kim et al., 2018). The phosphorene layer located above the Li surface spontaneously reacts with $\mathrm{Li}$ to form $\mathrm{Li}_{3} \mathrm{P}$. The phosphorene-coated Li metal electrode displayed a constant capacity of $1,000 \mathrm{mAh} \mathrm{g}^{-1}$ with no capacity reduction even after 50 cycles for the $\mathrm{Li}-\mathrm{O}_{2}$ battery. The $\mathrm{Li}_{3} \mathrm{P}$ protective layer effectively suppressed $\mathrm{Li}$ dendrites in terms of thermodynamics. However, the $\mathrm{Li}_{3} \mathrm{P}$ artificial solid electrolyte interphase (SEI) layer constructed by a simple spin coating method is not strong enough to continually resist the growth of Li dendrites. Tang et al. deposited Si on the Li surface by using a magnetron sputtering system. The bottom of the Li foil was heated to make Si reacting with $\mathrm{Li}$ and $\mathrm{Li}_{\mathrm{X}} \mathrm{Si}$ layer was obtained (Tang et al., 2018). In the symmetric cells, stable cycling performance was achieved for the $\mathrm{Li}_{\mathrm{x}} \mathrm{Si} @ \mathrm{Li}$ electrode over $400 \mathrm{~h}$ at the current density of $1 \mathrm{~mA} \mathrm{~cm}{ }^{-2}$. It was demonstrated that the coated $\mathrm{Li}_{\mathrm{X}} \mathrm{Si}$ layer led Li ions distributed uniformly on the surface of the Li metal anode during cycling. Nevertheless, the fabrication technology of the $\mathrm{Li}_{\mathrm{x}} \mathrm{Si} \mathrm{QLi}$ electrode is quite complicated, which hinders its practical application. Generally, metals have excellent electrical conductivity. It is well-known that $\mathrm{Ag}$ has a good wettability with $\mathrm{Li}$ and excellent electrical conductivity compared to other metals in the previous report (Zhang X. Q. et al., 2018; Song et al., 2019).

Herein, a thin Ag layer was coated on the Li foil surface (Ag@Li) by thermal evaporation. Due to this modified Ag layer, Li ions deposited uniformly on the surface and therefore Li dendrites were effectively suppressed during cycling. The symmetric cells using the Ag@Li electrodes displayed superior cycling performance for $85 \mathrm{~h}$ at a high current density of $5 \mathrm{~mA}$ $\mathrm{cm}^{-2}$. The full cells assembled with $\mathrm{LiFePO}_{4}(\mathrm{LFP})$ as cathodes exhibited a capacity retention of $92 \%$ after 300 cycles.
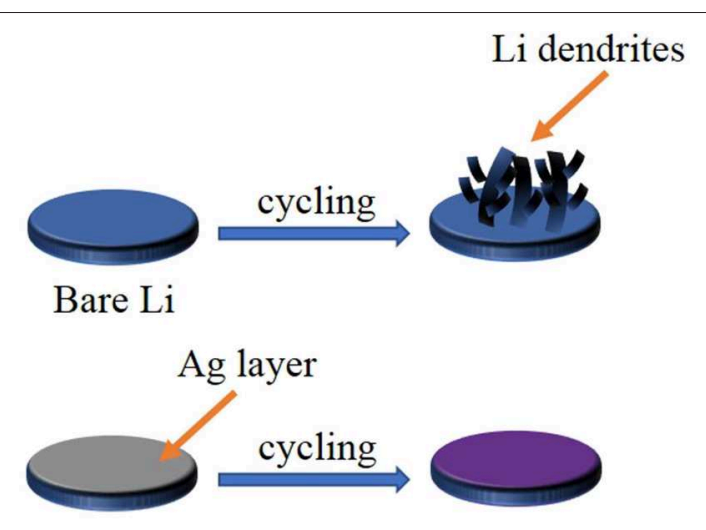

Ag-coated Li

FIGURE 1 | Schematic illustration of bare Li and Ag@Li discs during cycling process.

\section{EXPERIMENTAL SECTION}

\section{Preparation of the Ag@Li Electrode}

A 0.6 mm-thick Li tape (Tianjin Zhongneng Lithium Co. Ltd.) was cut into $\mathrm{Li}$ discs with a diameter of $16 \mathrm{~mm}$ in an argonfilled glovebox. The cut Li discs were transferred to the thermal evaporation equipment connected with the glovebox. The Ag@Li discs were fabricated by using a ZD-450 single-chamber sixsource resistive evaporation equipment with $\mathrm{Ag}$ metal as source at a current density of $88 \mathrm{~mA}$ under $1.0 \times 10^{-4} \mathrm{~Pa}$. Specifically, the Li discs were fixed on the substrate holder, and the Ag metal was placed in the tungsten boat. Deposition rate set to $0.1 \AA \mathrm{s}^{-1}$.

\section{Materials Characterization}

The microstructure and element distribution of the bare Li and the Ag@Li discs before and after electrochemical plating, and after 50 cycles was observed by scanning electron microscope (SEM, TESCAN MIR A3) equipped with energy dispersive spectroscopy (EDS). The X-ray diffraction (XRD) analysis was characterized using a Rigaku Ultima IV at $40 \mathrm{kV}$ and $40 \mathrm{~mA}$ with a scan rate of $5^{\circ} \mathrm{min}^{-1}(\mathrm{Cu} \mathrm{K \alpha} \mathrm{X}$-ray radiation source).

\section{Electrochemical Characterization}

CR2016-type coin cells were assembled using Ag@Li discs as the working electrodes and bare $\mathrm{Li}$ foil as the counter electrodes. $1 \mathrm{M}$ lithium bis(trifluoreomethane)sulfonamide (LiTFSI) in 1,3-dioxolane/1.2-dimethoxyethane (DOL/DME, 1:1 by volume) with $1 \% \mathrm{LiNO}_{3}$ and $1 \mathrm{M} \mathrm{LiPF} 6$ in ethylene carbonate/diethyl carbonate (EC/DEC/EMC, 1:1:1 by volume) were used as the electrolytes. The amount of electrolyte was 50 $\mu \mathrm{L}$. Electrochemical performance of the Li|Li symmetric cells and $\mathrm{LiFePO}_{4} \mid \mathrm{Li}$ full cells were tested using Shenzhen Neware battery testing system. Electrochemical impendence spectroscopy (EIS) measurements were investigated by IVIUMnSTAT electrochemical workstation with a frequency range from $100 \mathrm{kHz}$ to $0.01 \mathrm{~Hz}$ at voltage amplitude of $10 \mathrm{mV}$. The active material $\mathrm{LiFePO}_{4}$, super $\mathrm{P}$ conductive carbon and polyvinylidene fluoride (PVDF) were mixed in the weight 
ratio of $8: 1: 1$ as the cathode materials. The loading mass of $\mathrm{LiFePO}_{4}$ was $\sim 1 \mathrm{mg} \mathrm{cm}{ }^{-2}$. Galvanostatic charge/discharge cycling tests of the full cells were carried out in a potential range of $2.4-4.2 \mathrm{~V}$ at $0.5 \mathrm{C}$. The rate performance of $\mathrm{LiFePO}_{4} \mid \mathrm{Li}$ full cell was tested under $0.5,1,2,3,5,10 \mathrm{C}$ then back to $1 \mathrm{C}$.

\section{RESULTS AND DISCUSSION}

Figure 1 shows the schematic illustration of the bare Li and the Ag@Li electrodes during cycling process. For the unprotected Li disc, an uneven SEI layer appeared due to the inhomogeneous Li ions flux, resulting in $\mathrm{Li}$ dendrites growth, which leads to the internal short circuit of the batteries. In contrast, with the deposition of Ag on Li metal (Ag@Li), the electrode surface is much flatter during the charge/discharge process. The lithiophilic $\mathrm{Ag}$ layer can induce uniform deposition of $\mathrm{Li}$ ions, therefore inhibiting the growth of $\mathrm{Li}$ dendrites and achieving excellent cycling performances of LMBs.

As illustrated in Figure 2a, there is a distinct change in color from silvery white to black after Ag layer coated on the Li foil. From the XRD results in Figure $2 \mathbf{b}$, the diffraction peaks at $38.1^{\circ}$ and $44.3^{\circ}$ refer to the (111) and (220) crystal planes of $\mathrm{Ag}$, indicating that $\mathrm{Ag}$ layer have been coated on the bare Li disc. SEM images were characterized to observe the microstructure of the bare Li and the Ag@Li anodes. From Figures 2c,f, the surface of bare Li is very smooth without impurities. After the thermal evaporation deposition of $\mathrm{Ag}$, the Li surface is covered with Ag particles with a size of about $1 \mu \mathrm{m}$ (Figure 2d). As shown in Figure 2g, a thin Ag layer with the thickness of around $6.1 \mu \mathrm{m}$ is coated uniformly on the Li metal surface. Ag element distributions shown in Figures 2e,h illustrate that the Ag particles and the coated Ag layer are also distributed uniformly on the Li surface, corresponding with the SEM images in Figures 2d,g.
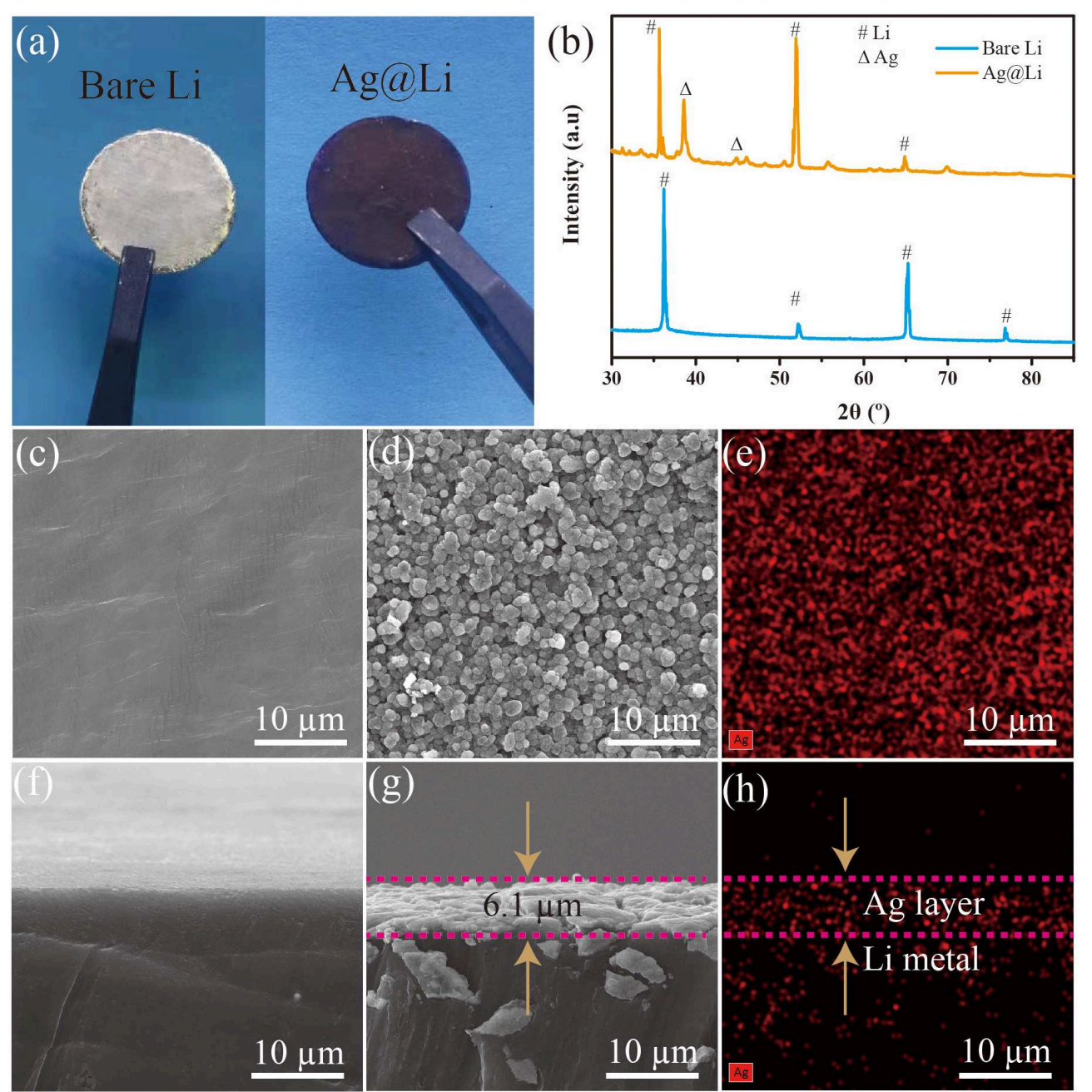

FIGURE 2 | (a) Optical photographs and (b) XRD patterns of bare Li and Ag@Li electrodes; (c) SEM images of the surface and (f) cross section of bare Li electrode; (d) SEM images of the surface and (g) cross section of the Ag@Li electrode; (e) Element distributions of Ag on the surface and (h) cross section of Ag@Li electrode. 

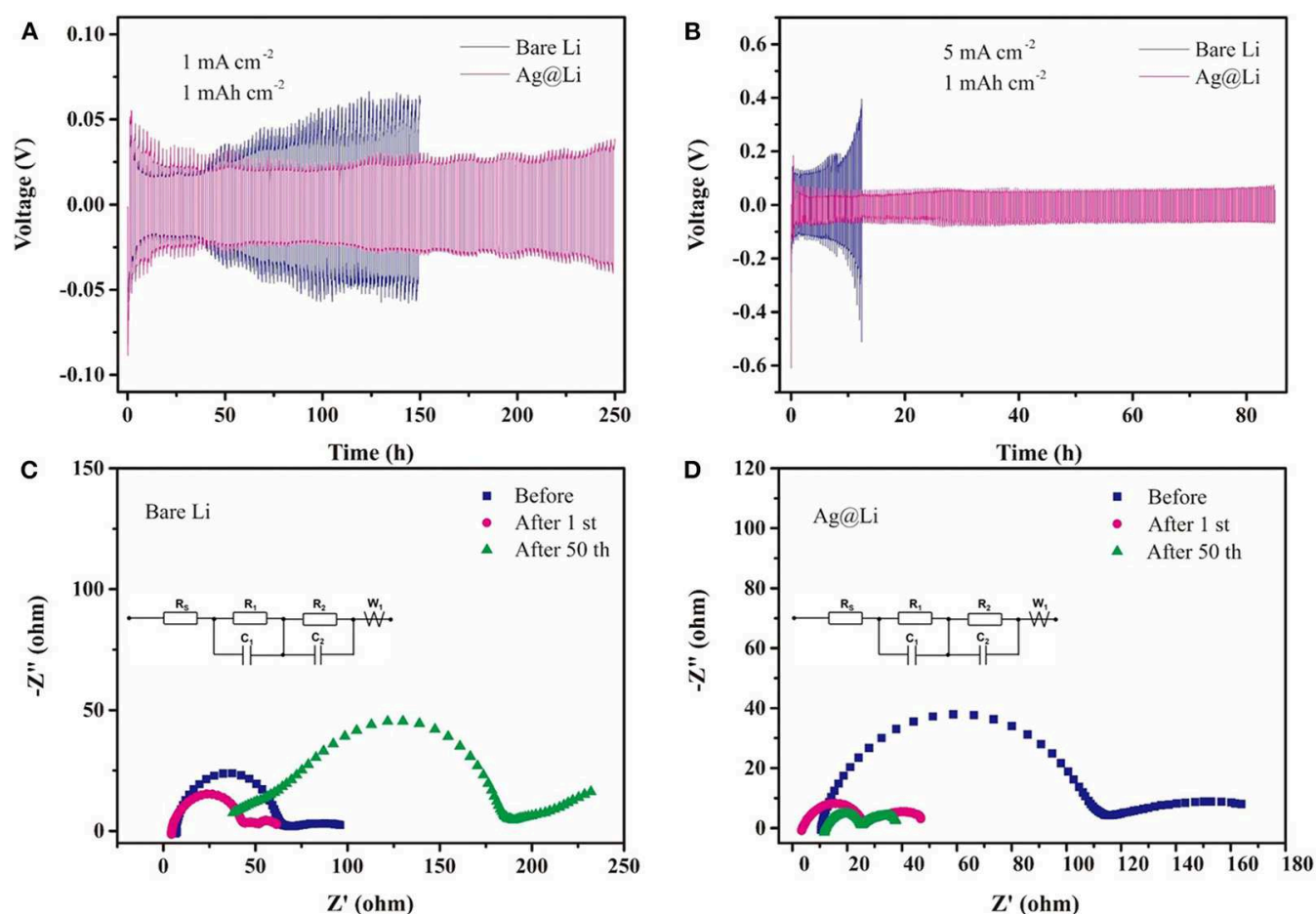

FIGURE 3 | Voltage-time profiles of the Li plating/stripping process in symmetric Li|Li and Ag@Li|Ag@Li cells at different current densities of (A) 1 mA cm ${ }^{-2}$ and (B) $5 \mathrm{~mA} \mathrm{~cm}^{-2}$. The capacity is fixed at $1 \mathrm{mAh} \mathrm{cm}^{-2}$. ElS curves and equivalent circuit of the symmetric cells with (C) bare Li and (D) Ag@Li electrodes during cycling at the current density of $1 \mathrm{~mA} \mathrm{~cm}^{-2}$ and a fixed capacity of $1 \mathrm{mAh} \mathrm{cm}^{-2}$.
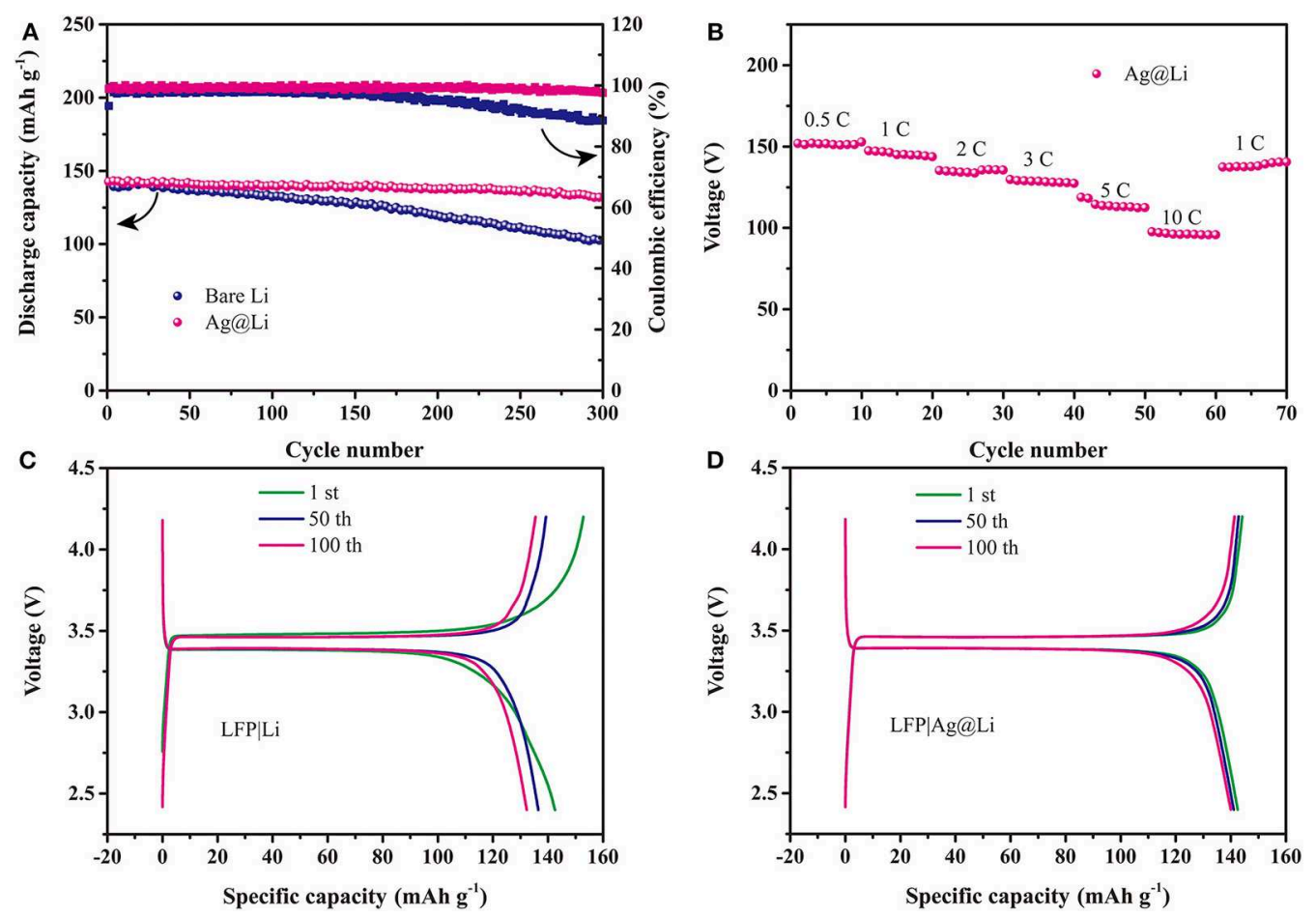

FIGURE 4 | (A) Cycling performance of the LFP|Li and LFP|Ag@Li cells at 0.5 C. (B) Rate performance of the LFP|Ag@Li cell. Charge/discharge profiles of the (C) LFP|Li and (D) LFP|Ag@Li cells after 1st, 50th, and 100th cycles at $0.5 \mathrm{C}$. 

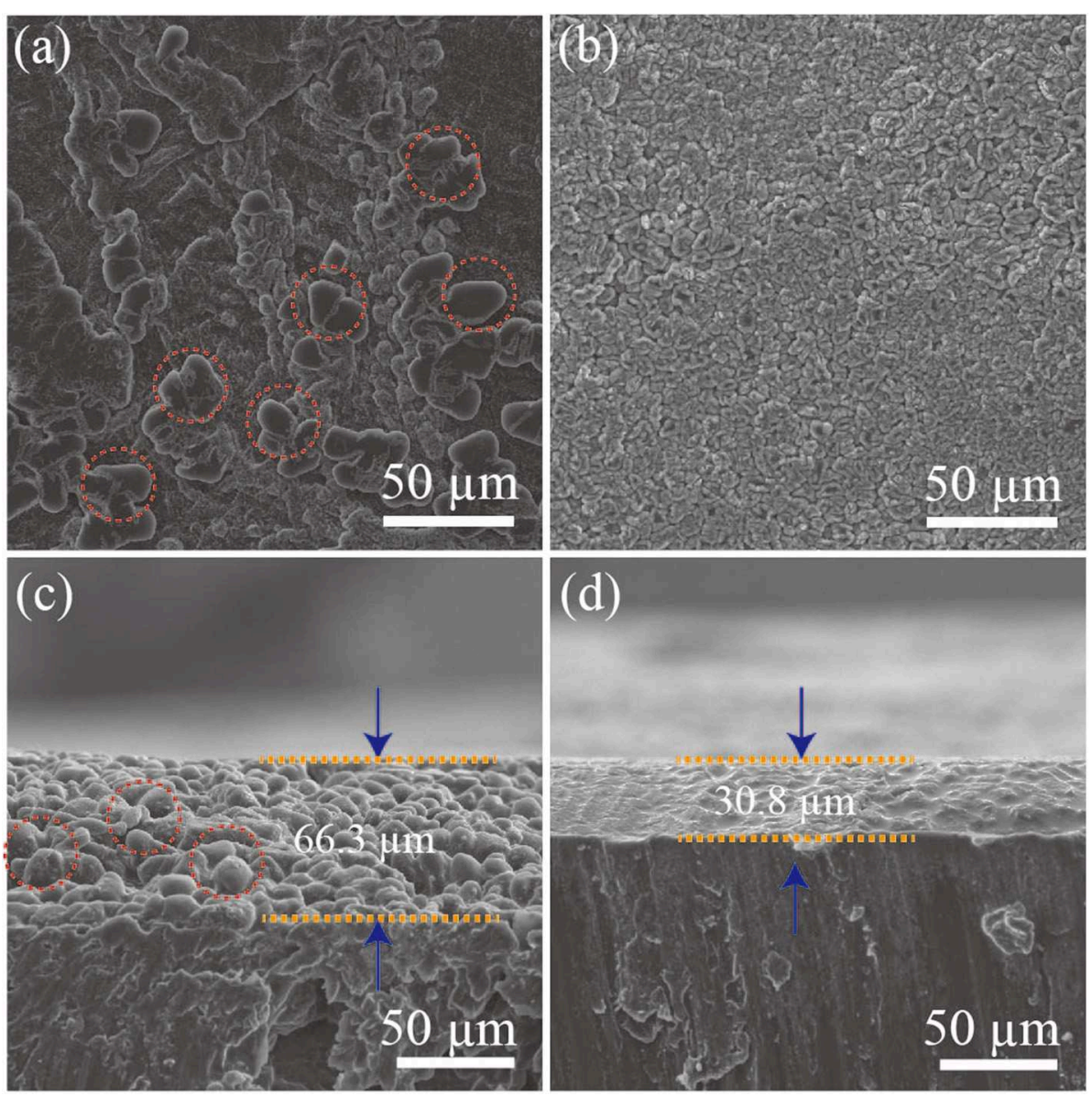

FIGURE 5 | SEM images of the surface of (a) bare Li and (b) Ag@Li. Cross-sectional SEM images of (c) bare Li and (d) Ag@Li. Symmetric cells are discharged at a current density of $2.5 \mathrm{~mA} \mathrm{~cm}^{-2}$ with a fixed capacity of $5 \mathrm{mAh} \mathrm{cm}^{-2}$.

The symmetric cells are constructed to test the variation of polarization voltage using the bare Li and the Ag@Li electrodes. As shown in the Figure 3A, the $\mathrm{Li} \mid \mathrm{Li}$ symmetric cell appears an increased overpotential after $50 \mathrm{~h}$. By comparison, the cell using the Ag@Li electrode exhibits larger polarization overpotential during the initial several cycles. However, the voltage hysteresis of the symmetric cell with the Ag@Li electrode decreases in the first $50 \mathrm{~h}$ and keeps stable at $38 \mathrm{mV}$ even after $250 \mathrm{~h}$, indicating that the cell with the Ag@Li electrode possessed good cycling electrochemical performance. When it comes to higher current density $\left(5 \mathrm{~mA} \mathrm{~cm}{ }^{-2}\right)$ (Figure 3B), the cell with the bare Li anode shows considerable overpotential (from 140 to $400 \mathrm{mV}$ ) during Li plating/string process. In contrast, the Ag@Li electrode exhibits much lower overpotential and more stable electrochemical performance. It is worth noting that the cell with the bare Li electrode gets short-circuited in only $12 \mathrm{~h}$ at high current density of $5 \mathrm{~mA} \mathrm{~cm}{ }^{-2}$ due to the $\mathrm{Li}$ dendrite growth. As for the Ag@Li electrode, the Ag layer constructed on the surface of Li metal leads to uniform deposition of Li ions, which is effectively improve the stability of Li metal. EIS curves and equivalent circuit of the symmetric cells with bare Li and Ag@Li electrodes during cycling at the current density of $1 \mathrm{~mA} \mathrm{~cm}^{-2}$ are shown in Figures 3C,D. The electrolyte resistance (Rs) of the $\mathrm{Li} \mid \mathrm{Li}$ cell decrease first and then increases to $38 \Omega$, while the Rs of Ag@Li|Ag@Li cell is smaller than that of the Li|Li cell after 50 cycles, respectively. The SEI resistance $\left(\mathrm{R}_{\mathrm{f}}\right)$ is consisted of the high frequency region $R_{1}$ and the low frequency region $R_{2}$. The $\mathrm{R}_{\mathrm{f}}$ of the $\mathrm{Li} \mid \mathrm{Li}$ cell shows a increasing trend and finally comes to as high as $154 \Omega$ after 50 cycles. As for the Ag@Li|Ag@Li cell, $\mathrm{R}_{\mathrm{f}}$ is nearly $120 \Omega$ before cycling but it decreases sharply to $33 \Omega$ and keep steadily after 50 cycles.

Figure 4A displays the cycling performance of the LFP $\mid \mathrm{Li}$ and LFP|Ag@Li cells at $0.5 \mathrm{C}$. An initial capacity of $142 \mathrm{mAh} \mathrm{g}^{-1}$ and a capacity retention ratio of $92 \%$ after 300 cycles are obtained for the LFP|Ag@Li full cell at $0.5 \mathrm{C}$, while the capacity retention ratio of LFP|Li cell is nearly 71\%, showing that the full cell with Ag@Li electrode is more stable during cycling. Figure 4B presents the rate performance of the full cells with Ag@Li electrode. It can be seen that the capacity of LFP|Ag@Li cell keep stable at different current density even at $10 \mathrm{C}$. The galvanostatic charge-discharge curves of LFP|Li and LFP|Ag@Li cells after 1st, 50th, and 100th cycles are shown in Figures 4C,D. The full cell with Ag@Li 

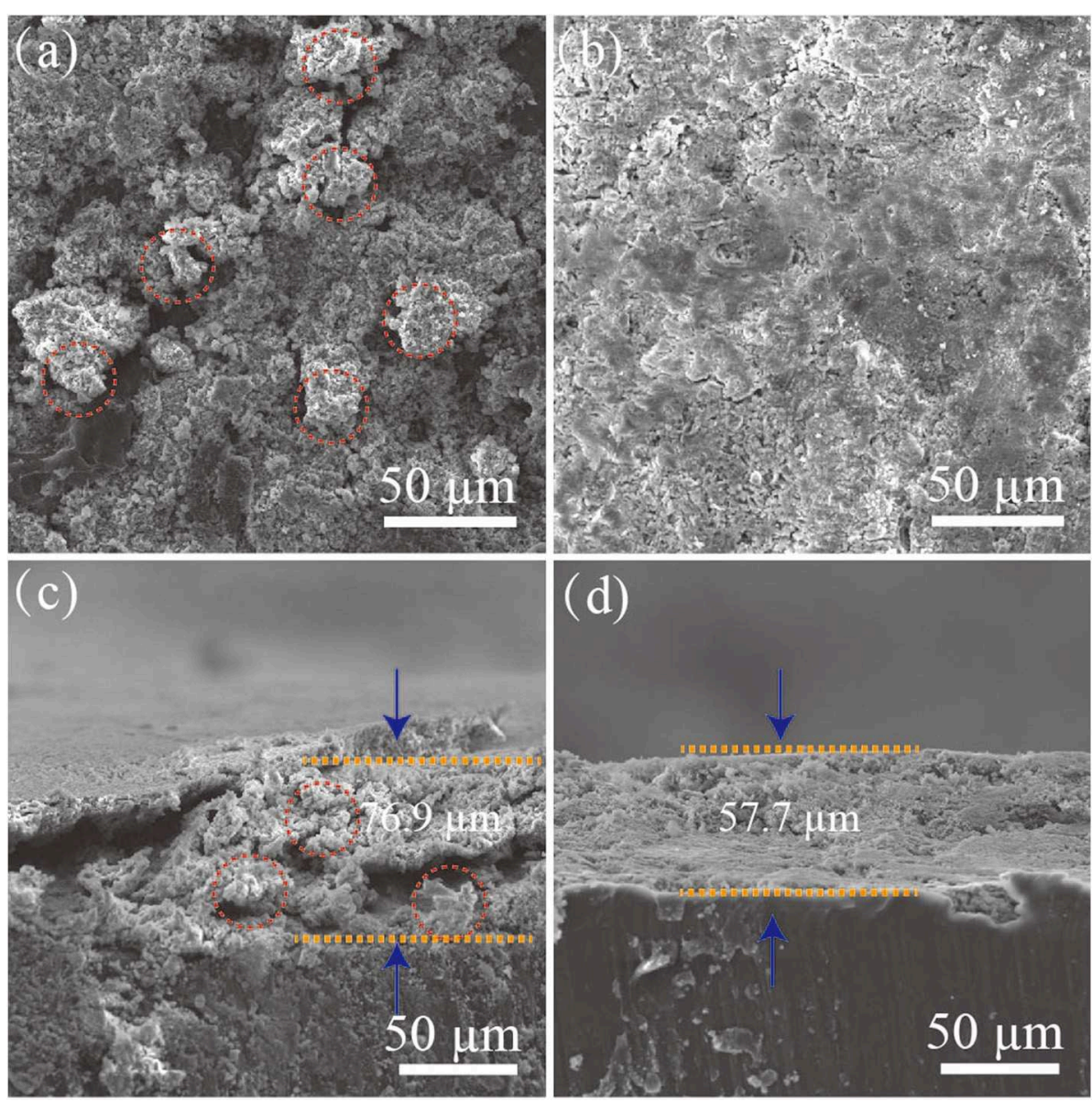

FIGURE 6 | Surficial SEM images of (a) the bare Li and (b) the Ag@Li electrode. Cross-sectional SEM images of (c) the bare Li and (d) the Ag@Li electrodes in the symmetric cells after 50 cycles at a current density of $1 \mathrm{~mA} \mathrm{~cm}{ }^{-2}$ with a fixed capacity of $1 \mathrm{mAh} \mathrm{cm^{-2 }}$.

TABLE 1 | Summary of the overpotential of the cells with modified Li metal anodes.

\begin{tabular}{|c|c|c|c|c|}
\hline Anode & $\begin{array}{l}\text { Current density } \\
\qquad\left(\mathrm{mA} \mathrm{cm}^{-2}\right)\end{array}$ & 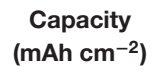 & $\begin{array}{l}\text { Overpotential } \\
\text { (mV) }\end{array}$ & References \\
\hline $\mathrm{Li}_{2} \mathrm{~S} @ \mathrm{Li}$ & 2 & 5 & 95 & Chen H. et al., 2019 \\
\hline Li $i_{3} P @ L i$ & 0.1 & 0.5 & 60 & Kim et al., 2018 \\
\hline Li/Cu-VAMCs & 1 & 1 & 20 & Wang S. H. et al., 2017 \\
\hline
\end{tabular}

electrode is more stable and shows lower polarization voltage than of the full cell with bare Li electrode.

To further study the Li metal electrochemical deposition, a symmetric cell was discharged at a current density of $2.5 \mathrm{~mA}$ $\mathrm{cm}^{-2}$ with a fixed capacity of $5 \mathrm{mAh} \mathrm{cm}^{-2}$. As shown in Figure $5 \mathrm{a}, \mathrm{Li}$ dendrites are detected on the surface of the pristine $\mathrm{Li}$ foil during the deposition process. It is noteworthy that $\mathrm{Li}$ dendrites tend to fill the interspace among the $\mathrm{Ag}$ particles, resulting in the lateral growth on the surface of Ag@Li electrode (Figure 5b). Moreover, obvious Li dendrites with a thickness of $\sim 66.3 \mu \mathrm{m}$ are detected from the cross-sectional SEM image for the bare Li electrode after 50 cycles (Figure $5 \mathbf{c}$ ), while the Ag@Li electrode shows a dense Ag-Li alloy layer of $\sim 30.8 \mu \mathrm{m}$ without any $\mathrm{Li}$ dendrites on the electrode surface (Figure 5d). The remarkable Li dendrites inhibition ability of the Ag@Li layer is mainly caused by the strong affinity of Li with Ag, which can induce uniform deposition of Li ions during electrochemical cycling.

Figure 6 shows the SEM images of the bare Li and the Ag@Li electrodes after 50 cycles at a current density of $1 \mathrm{~mA} \mathrm{~cm}^{-2}$ and a 
fixed capacity of $1 \mathrm{mAh} \mathrm{cm}^{-2}$. The Ag@Li electrode has a flatter surface compare to that of the bare Li. From the cross-section images, cracks and dendrites emerged on the bare Li electrode surface due to the volume changes during the Li plating/string process. Oppositely, the Ag@Li electrode demonstrates a smooth boundary layer with a thickness of $57.7 \mu \mathrm{m}$.

Table 1 summaries the overpotential of the cells with modified Li metal anodes in recent literatures. By comparison, the overpotential of cells with Ag@Li anode in this work is $38 \mathrm{mV}$, which is competitive with other kinds of modified Li metal anode.

\section{CONCLUSIONS}

In this work, a thin lithiophilic Ag layer was coated on the bare Li surface by using thermal evaporation deposition to inhibit $\mathrm{Li}$ dendrites growth. The lithiophilic Ag layer provides Li nucleation sites to regulate $\mathrm{Li}$ ions flux for $\mathrm{Li}$ deposition. The excellent electrical conductivity of $\mathrm{Ag}$ also improves the Li ions transport capacity. The Ag@Li|Ag@Li symmetric cell shows great cycling over $85 \mathrm{~h}$ at current density up to $5 \mathrm{~mA} \mathrm{~cm}^{-2}$. After 300 cycles, a capacity retention ratio of nearly $92 \%$ is achieved in the LFP full cell. This research gives us a new inspiration for improving the lifetime and safety of the Li metal batteries.

\section{REFERENCES}

Aurbach, D., Zinigrad, E., Teller, H., Cohen, Y., Salitra, G., Yamin, H., et al. (2002). Attempts to improve the behavior of $\mathrm{Li}$ electrodes in rechargeable lithium batteries. J. Electrochem. Soc. 149, A1267-A1277. doi: 10.1149/1.1502684

Bouchet, R., Maria, S., Meziane, R., Aboulaich, A., Lienafa, L., Bonnet, J.-P., et al. (2013). Single-ion BAB triblock copolymers as highly efficient electrolytes for lithium-metal batteries. Nat. Mater. 12, 452-457. doi: 10.1038/nmat3602

Chen, H., Pei, A., Lin, D., Xie, J., Yang, A., Xu, J., et al. (2019). Uniform high ionic conducting lithium sulfide protection layer for stable lithium metal anode. Adv. Energy Mater. 9:1900858. doi: 10.1002/aenm.201900858

Chen, X., He, W., Ding, L.-X., Wang, S., and Wang, H. (2019). Enhancing interfacial contact in all solid state batteries with a cathode-supported solid electrolyte membrane framework. Energy Environ. Sci. 12, 938-944. doi: 10.1039/C8EE02617C

Cheng, X.-B., Zhang, R., Zhao, C.-Z., and Zhang, Q. (2017). Toward safe lithium metal anode in rechargeable batteries: a review. Chem. Rev. 117, 10403-10473. doi: 10.1021/acs.chemrev.7b00115

Choi, J. W., and Aurbach, D. (2016). Promise and reality of post-lithiumion batteries with high energy densities. Nat. Rev. Mater. 1:16013. doi: 10.1038/natrevmats.2016.13

Choi, N. S., Chen, Z., Freunberger, S. A., Ji, X., Sun, Y. K., Amine, K., et al. (2012). Challenges facing lithium batteries and electrical double-layer capacitors. Angew. Chem. Int. Ed. Engl. 51, 9994-10024. doi: 10.1002/anie.201201429

Goodenough, J. B., and Park, K.-S. (2013). The Li-ion rechargeable battery: a perspective. J. Am. Chem. Soc. 135, 1167-1176. doi: 10.1021/ja3091438

Grande, L., von Zamory, J., Koch, S. L., Kalhoff, J., Paillard, E., and Passerini, S. (2015). Homogeneous lithium electrodeposition with Pyrrolidiniumbased ionic liquid electrolytes. ACS Appl. Mater. Interfaces 7, 5950-5958. doi: 10.1021/acsami.5b00209

Guo, F., Wu, C., Chen, H., Zhong, F., Ai, X., Yang, H., et al. (2019). Dendrite-free lithium deposition by coating a lithiophilic heterogeneous metal layer on lithium metal anode. Energy Storage Mater. 24, 635-643. doi: 10.1016/j.ensm.2019.06.010

Guo, Y., Li, H., and Zhai, T. (2017). Reviving lithium-metal anodes for next-generation high-energy batteries. Adv. Mater. 29:1700007. doi: 10.1002/adma.201700007

\section{DATA AVAILABILITY STATEMENT}

All datasets generated for this study can be found in the article.

\section{AUTHOR CONTRIBUTIONS}

$\mathrm{ZZ}$ and LZ contributed equally to this work. BT, ZZ, and LZ designed this work. ZZ synthesized the electrode and carried out the experiment. ZZ, LZ, and BT cowrote the manuscript. All the authors gave useful suggestions, discussed the results and commented on the manuscript.

\section{FUNDING}

This work was supported by Natural Science Foundation of China (21968012), the Guangdong Natural Science Funds (2019A1515010675), Yunnan Natural Science Foundation (2019FB012), Yunnan Talent Reserve Project (2015HB022), Science and Technology Project of Shenzhen (JCYJ20180305125106329 and ZDSYS201707271014468), Shenzhen Peacock Plan (827-000273, KQJSCX20180328094001794, and KQTD2016053112042971).

Han, X., Gong, Y., Fu, K. K., He, X., Hitz, G. T., Dai, J., et al. (2017). Negating interfacial impedance in garnet-based solid-state Li metal batteries. Nat. Mater. 16, 572-579. doi: 10.1038/nmat4821

Jiang, Z., Xie, H., Wang, S., Song, X., Yao, X., and Wang, H. (2018). Perovskite membranes with vertically aligned microchannels for all-solid-state lithium batteries. Adv. Energy Mater. 8:1801433. doi: 10.1002/aenm.201801433

Kamaya, N., Homma, K., Yamakawa, Y., Hirayama, M., Kanno, R., Yonemura, M., et al. (2011). A lithium superionic conductor. Nat. Mater. 10, 682-686. doi: $10.1038 /$ nmat3066

Kim, Y., Koo, D., Ha, S., Jun, S. C., Yim, T., Kim, H., et al. (2018). Two-dimensional phosphorene-derived protective layers on a lithium metal anode for lithiumoxygen batteries. ACS Nano 12, 4419-4430. doi: 10.1021/acsnano.8b00348

Li, W., Yao, H., Yan, K., Zheng, G., Liang, Z., Chiang, Y.-M., et al. (2015). The synergetic effect of lithium polysulfide and lithium nitrate to prevent lithium dendrite growth. Nat. Commun. 6:7436. doi: 10.1038/ncomms8436

Li, Y., Yang, J., and Song, J. (2016). Nano-energy system coupling model and failure characterization of lithium ion battery electrode in electric energy vehicles. Renew. Sustain. Energy Rev. 54, 1250-1261. doi: 10.1016/j.rser.2015.10.070

Liang, J., Li, X., Zhao, Y., Goncharova, L. V., Li, W., Adair, K. R., et al. (2019). An air-stable and dendrite-free $\mathrm{Li}$ anode for highly stable all-solid-state sulfidebased Li batteries. Adv. Energy Mater. 9:1902125. doi: 10.1002/aenm.2019 02125

Lin, D., Liu, Y., and Cui, Y. (2017). Reviving the lithium metal anode for highenergy batteries. Nat. Nanotechnol. 12, 194-206. doi: 10.1038/nnano.2017.16

Lin, L., Liang, F., Zhang, K., Mao, H., Yang, J., and Qian, Y. (2018). Lithium phosphide/lithium chloride coating on lithium for advanced lithium metal anode. J. Mater. Chem. A 6, 15859-15867. doi: 10.1039/C8TA05102J

Qi, L.-Y., Shang, L., Chen, X., Ye, L., Zhang, W., Feng, P., et al. (2018). A versatile strategy to fabricate 3D conductive frameworks for lithium metal anodes. $A d v$. Mater. Interfaces 5:1800807. doi: 10.1002/admi.201800807

Qian, J., Henderson, W. A., Xu, W., Bhattacharya, P., Engelhard, M., Borodin, O., et al. (2015). High rate and stable cycling of lithium metal anode. Nat. Commun. 6:6362. doi: $10.1038 /$ ncomms 7362

Sahalie, N. A., Assegie, A. A., Su, W.-N., Wondimkun, Z. T., Jote, B. A., Thirumalraj, B., et al. (2019). Effect of bifunctional additive potassium nitrate on performance of anode free lithium metal battery in carbonate electrolyte. J. Power Sources 437:226912. doi: 10.1016/j.jpowsour.2019.226912 
Schmuch, R., Wagner, R., Hörpel, G., Placke, T., and Winter, M. (2018). Performance and cost of materials for lithium-based rechargeable automotive batteries. Nat. Energy 3, 267-278. doi: 10.1038/s41560-018-0107-2

Song, H., Chen, X., Zheng, G., Yu, X., Jiang, S., Cui, Z., et al. (2019). Dendrite-free composite $\mathrm{Li}$ anode assisted by $\mathrm{Ag}$ nanoparticles in a wood-derived carbon frame. ACS Appl. Mater. Interfaces 11, 18361-18367. doi: 10.1021/acsami.9b01694

Takeda, Y., Yamamoto, O., and Imanishi, N. (2016). Lithium dendrite formation on a lithium metal anode from liquid, polymer and solid electrolytes. Electrochemistry 84, 210-218. doi: 10.5796/electrochemistry.84.210

Tang, W., Yin, X., Kang, S., Chen, Z., Tian, B., Teo, S. L., et al. (2018). Lithium silicide surface enrichment: a solution to lithium metal battery. Adv. Mater. 30:1801745. doi: 10.1002/adma.201801745

Tarascon, J.-M., and Armand, M. (2011). Issues and challenges facing rechargeable lithium batteries. Mater. Sustain. Energy Appl. 24, 171-179. doi: 10.1142/9789814317665_0024

Wang, A., Tang, S., Kong, D., Liu, S., Chiou, K., Zhi, L., et al. (2018). Bending-tolerant anodes for lithium-metal batteries. Adv. Mater. 30:1703891. doi: 10.1002/adma.201703891

Wang, H., Matsui, M., Kuwata, H., Sonoki, H., Matsuda, Y., Shang, X., et al. (2017). A reversible dendrite-free high-areal-capacity lithium metal electrode. Nat. Commun. 8:15106. doi: 10.1038/ncomms15106

Wang, L., Zhu, X., Guan, Y., Zhang, J., Ai, F., Zhang, W., et al. (2018). $\mathrm{ZnO} /$ carbon framework derived from metal-organic frameworks as a stable host for lithium metal anodes. Energy Storage Mater. 11, 191-196. doi: 10.1016/j.ensm.2017.10.016

Wang, S. H., Yin, Y. X., Zuo, T. T., Dong, W., Li, J. Y., Shi, J. L., et al. (2017). Stable Li metal anodes via regulating lithium plating/stripping in vertically aligned microchannels. Adv. Mater. 29:1703729. doi: 10.1002/adma.201 703729

Whittingham, M. S. (1976). Electrical energy storage and intercalation chemistry. Science 192, 1126-1127. doi: 10.1126/science.192.4244.1126

Xia, S., Zhang, X., Liang, C., Yu, Y., and Liu, W. (2019). Stabilized lithium metal anode by an efficient coating for high-performance LiS batteries. Energy Storage Mater. 24, 329-335. doi: 10.1016/j.ensm.2019.07.042

Xiang, H., Chen, J., Li, Z., and Wang, H. (2011). An inorganic membrane as a separator for lithium-ion battery. J. Power Sources 196, 8651-8655. doi: 10.1016/j.jpowsour.2011.06.055

Xu, W., Wang, J., Ding, F., Chen, X., Nasybulin, E., Zhang, Y., et al. (2014). Lithium metal anodes for rechargeable batteries. Energy \& Environ. Sci. 7, 513-537. doi: $10.1039 / \mathrm{c} 3 e e 40795 \mathrm{k}$

Xue, W., Shi, Z., Suo, L., Wang, C., Wang, Z., Wang, H., et al. (2019a). Intercalation-conversion hybrid cathodes enabling $\mathrm{Li}-\mathrm{S}$ full-cell architectures with jointly superior gravimetric and volumetric energy densities. Nat. Energy 4:374. doi: 10.1038/s41560-019-0351-0

Xue, W., Yu, D., Suo, L., Wang, C., Wang, Z., Xu, G., et al. (2019b). Manipulating sulfur mobility enables advanced Li-S batteries. Matter 1, 1047-1060. doi: 10.1016/j.matt.2019.07.002

Yan, K., Lu, Z., Lee, H.-W., Xiong, F., Hsu, P.-C., Li, Y., et al. (2016). Selective deposition and stable encapsulation of lithium through heterogeneous seeded growth. Nat. Energy 1:16010. doi: 10.1038/nenergy.2016.10

Yang, C.-P., Yin, Y.-X., Zhang, S.-F., Li, N.-W., and Guo, Y.-G. (2015). Accommodating lithium into $3 \mathrm{D}$ current collectors with a submicron skeleton towards long-life lithium metal anodes. Nat. commun. 6:8058. doi: 10.1038/ncomms 9058

Ye, H., Xin, S., Yin, Y.-X., Li, J.-Y., Guo, Y.-G., and Wan, L.-J. (2017). Stable $\mathrm{Li}$ plating/stripping electrochemistry realized by a hybrid $\mathrm{Li}$ reservoir in spherical carbon granules with 3D conducting skeletons. J. Am. Chem. Soc. 139, 5916-5922. doi: 10.1021/jacs.7b01763

Yue, X.-Y., Wang, W.-W., Wang, Q.-C., Meng, J.-K., Wang, X.-X., Song, Y., et al. (2018). Cuprite-coated $\mathrm{Cu}$ foam skeleton host enabling lateral growth of lithium dendrites for advanced Li metal batteries. Energy Storage Mater. 21, 180-189. doi: 10.1016/j.ensm.2018.12.007

Zhang, C., Lv, W., Zhou, G. M., Huang, Z. J., Zhang, Y. B., Lyu, R. Y., et al. (2018). Vertically aligned lithiophilic $\mathrm{CuO}$ nanosheets on a $\mathrm{Cu}$ collector to stabilize lithium deposition for lithium metal batteries. Adv. Energy Mater. 8:1703404 doi: 10.1002/aenm.201703404

Zhang, X. Q., Chen, X., Cheng, X.B., Li, B.Q., Shen, X., Yan, C., et al. (2018). Highly stable lithium metal batteries enabled by regulating the solvation of lithium ions in nonaqueous electrolytes. Angew. Chem. Int. Ed. 57, 5301-5305. doi: 10.1002/ange.201803003

Zheng, J., Engelhard, M.H., Mei, D., Jiao, S., Polzin, B.J., Zhang, J.-G., et al. (2017) Electrolyte additive enabled fast charging and stable cycling lithium metal batteries. Nat. Energy 2:17012. doi: 10.1038/nenergy.2017.12

Conflict of Interest: The authors declare that the research was conducted in the absence of any commercial or financial relationships that could be construed as a potential conflict of interest.

Copyright (c) 2020 Zuo, Zhuang, Xu, Shi, Su, Lian and Tian. This is an open-access article distributed under the terms of the Creative Commons Attribution License (CC $B Y)$. The use, distribution or reproduction in other forums is permitted, provided the original author(s) and the copyright owner(s) are credited and that the original publication in this journal is cited, in accordance with accepted academic practice No use, distribution or reproduction is permitted which does not comply with these terms. 